\title{
Diferenciações Regionais de Rendimentos do Trabalho: Uma Análise das Regiões Metropolitanas de São Paulo e de Salvador
}

\author{
Wilson F. Menezes \\ José Carrera-Fernandez \\ Cláudio Dedecca
}

\author{
Prof. do CME-UFBa e Doutor pela Université de Paris I \\ Prof. do CME-UFBa e PhD* pela The Univerty of Chicago \\ Prof. do IE-Unicamp e Doutor pela Unicamp
}

\begin{abstract}
RESUMO
Objetivando verificar a extensão dos diferenciais regionais de rendimentos sobre o mercado de trabalho, este artigo desenvolve uma análise comparativa para medir os principais elementos que diferenciam os rendimentos provenientes do trabalho entre as regiões metropolitanas de São Paulo (RMSP) e de Salvador (RMS). Com os dados da Pesquisa de Emprego e Desemprego (PED) para as duas regiões metropolitanas, buscou-se quantificar, pr meio da decomposição de Oaxaca, os diferenciais de rendimentos provenientes de distintas distribuições de atributos produtivos dos trabalhadores, separando-os dos diferenciais inerentes ao aspecto regional. Visando eliminar os possíveis vieses de seleção amostral, utilizou-se o procedimento de Heckman. Os resultados mostram um importante diferencial regional de rendimentos, para todos os agrupamentos de trabalhadores analisados, em favor dos trabalhadores da RMSP. Tais diferenciais de rendimento são decorrentes das sinergias vinculadas à maior concentração e aglomeração econômica da RMSP, relativamente à RMS. Observou-se ainda um diferencial significativo de rendimentos, também em favor dos trabalhadores da RMSP, decorrente da maior dotação dos atributos produtivos.
\end{abstract}

\section{PALAVRAS-CHAVE}

mercado de trabalho, diferenciais de rendimento, atributos produtivos, diferenciação regional

ABSTRACT

Aiming to verify the extent of regional differentials over the labor markets, this paper develops a comparative analyses to measure the main elements of differentiation of labor earnings between the metropolitan regions of São Paulo (RMSP) and Salvador (RMS). Taking the data from the Employment and Unemployment Research (PED) of these two metropolitan regions, we tried to estimate, through de Oaxaca decomposition, the labor income differentials resulting from different distribution of workers' productive attributes, splitting them from the differentials resulting from the regional aspects. Trying to eliminate the selectivity bias, we used the Heckman's proceduree. The results confirm the existence of an important regional differential of labor income for all group of workers analyzed, in benefit of workers of the MRSP. Such differentials of labor earnings result from the synergies associated to a larger economic concentration and conglomeration in the MRSP. Besides that, we observed a signifi-

cant differential of labor earnings for the worker from the MRSP, due to the larger endowment of workers' productive attributes

KEY WORDS labor market, labor income differentials, productive attributes, regional differentiation

JEL Classification

J3I, J44, J7I

EST. ECON., SÃO PAULO, V. 35, N. 2, P. 271-296, ABRIL-JUNHO 2005 


\section{INTRODUÇÃO}

A literatura brasileira tem registrado a preocupação de um grande número de autores no sentido de verificar a existência de desigualdades de rendimentos do trabalho, tanto no que se refere à segmentação do mercado de trabalho quanto no que concerne à discriminação por gênero e raça. Especificidades acerca de diferenciais de rendimento por gênero podem ser encontradas em Leme e Wajnman (2001); segundo inserção ocupacional foram objeto de estudo de Dedecca (2001); dos trabalhadores dos Estados Unidos e do Brasil podem ser vistas em Sacconato e Menezes Filho (2001); dos mercados de trabalho rurais e urbanos são analisadas em Loureiro e Carneiro (2001); dos mercados formais e informais de trabalho estão registradas em Silva e Kassouf (2000); e das regulamentações dos mercados de trabalho são tratadas em Fernandes (1996).

Estudos sobre diferenciais de rendimentos nos mercados de trabalho de regiões metropolitanas do País têm sido também feitos, entretanto tais estudos não têm buscado quantificar as possíveis diferenças regionais. Visando contribuir com o debate que se estabeleceu acerca desse tema, este ensaio procura identificar os diferenciais de rendimento associados às especificidades regionais embutidas nos mercados de trabalho das Regiões Metropolitanas de São Paulo (RMSP) e de Salvador (RMS), tomando-se como referência as informações da Pesquisa de Emprego e Desemprego (PED). Para tanto, desagregaram-se as amostras dessas duas regióes em quatro agrupamentos distintos de trabalhadores, de acordo com alguns atributos individuais.

Costuma-se dizer que diferenças regionais de rendimentos contribuem fortemente para tornar mais desigual a vida dos trabalhadores brasileiros. A despeito da relevância desse tema para a formação da renda no País, a literatura brasileira não tem buscado explicitar a importância dessas desigualdades regionais sobre os rendimentos do trabalho, limitando-se apenas a apontar seus possíveis efeitos sobre a distribuição de renda no País. Este trabalho encontra-se focado nessa questão, buscando informar até que ponto as influências regionais, provenientes de diferentes níveis de concentração e aglomeração econômica, são responsáveis por diferenciais significativos de rendimentos dos trabalhadores em regiões mais desenvolvidas, relativamente àqueles inseridos em regiões com estágios menos avançados de desenvolvimento.

Visando ampliar o conhecimento a esse respeito, determinam-se, por meio da decomposição de Oaxaca (1973), os diferenciais de rendimentos provenientes de possíveis diferenças nas distribuições de atributos observáveis relativos à inserção ocupacional dos trabalhadores, isolando-os dos elementos diferenciais inerentes ao aspecto regional. Buscando eliminar os prováveis vieses de seletividade amostral, que usualmente se observam quando somente trabalhadores ocupados e com rendimentos positivos são leva- 
dos em consideração na análise, utilizou-se o procedimento de Heckman (1970). Assim, estimaram-se, pelo método da máxima verossimilhança, equações de participação das pessoas no mercado de trabalho. Com base nos coeficientes estimados dessas equações de participação foi possível estimar a variável lambda ou razão inversa de Mills. Em seguida, adicionou-se essa nova variável às demais variáveis explicativas das equaçóes de rendimentos do trabalho. Este procedimento permite obter estimativas consistentes dos parâmetros das equações de rendimentos.

Além dessa introdução, este trabalho contém mais quatro seções e está organizado da seguinte forma. Na primeira seção exploram-se as informações estatísticas, visando proceder a uma caracterização regional dos dois mercados de trabalho analisados. $\mathrm{Na}$ seção seguinte descrevem-se o modelo adotado para decomposição dos diferenciais regionais de salários e os procedimentos econométricos utilizados para eliminar o viés de seleção amostral. Na terceira seção apresentam-se as estimativas e analisam-se os resultados obtidos. A última seção contém algumas considerações adicionais e conclusões deste trabalho, esperando que o mesmo possa contribuir para ampliar o conhecimento a respeito dos diferenciais regionais de rendimentos do trabalho no País.

\section{O MERCADO DE TRABALHO DAS RMSP E RMS}

Os mercados de trabalho das regiões metropolitanas de São Paulo e de Salvador mostram-se bastante diferenciados entre si e heterogêneos em seus interiores. As transformações econômicas da década de 1990 induziram modificações importantes em ambos os mercados, que conheceram uma duplicação de suas taxas de desemprego total.

A piora das condiçôes de funcionamento desses mercados de trabalho refletiu-se, em especial, sobre a composição do desemprego na RMSP, que conheceu uma queda da participação relativa do desemprego aberto no desemprego total. Assim, o desemprego oculto por trabalho precário ganhou maior importância, aproximando a situação desse mercado àquela vivida pela Região Metropolitana de Salvador (Tabela 1). 
TABELA 1 - TAXAS E DISTRIBUIÇÃO DE EMPREGO POR TIPO DE DESEMPREGO PARA AS REGIÓES METROPOLITANAS DE SÃO PAULO E SALVADOR

\begin{tabular}{|c|c|c|c|c|c|c|}
\hline \multirow[t]{2}{*}{ Regiões Metropolitanas } & \multicolumn{3}{|c|}{ Taxas } & \multicolumn{3}{|c|}{ Distribuiç̧ão } \\
\hline & Total & Aberto & Oculto & Total & Aberto & Oculto \\
\hline \multicolumn{7}{|l|}{ São Paulo } \\
\hline 1989 & 8,7 & 6,5 & 2,2 & 100,0 & 74,5 & 25,5 \\
\hline 2000 & 17,6 & 11,0 & 6,6 & 100,0 & 62,6 & 37,4 \\
\hline \multicolumn{7}{|l|}{ Salvador } \\
\hline 1989 & 16,3 & 9,0 & 7,3 & 100,0 & 55,2 & 44,8 \\
\hline 2000 & 26,6 & 15,0 & 11,6 & 100,0 & 56,4 & 43,6 \\
\hline
\end{tabular}

Fonte: (1) Pesquisa de Emprego e Desemprego (PED), São Paulo e Salvador, microdados.

(2) DEDECCA, FERREIRA \& RODRIGUES (1990).

O comportamento do desemprego em ambas as regiões demonstra a importância de considerá-lo segundo suas formas diversas de manifestação, pois seu aumento é acompanhado de uma menor relevância do desemprego aberto, em especial na Região Metropolitana de São Paulo, que em 1989 possuía um mercado de trabalho com uma maior participação de assalariados vinculados a empreendimentos de porte elevado.

TABELA 2 - TAXAS DE EMPREGO TOTAL POR SEXO E IDADE PARA AS REGIÕES METROPOLITANAS DE SÃO PAULO E SALVADOR

\begin{tabular}{|c|c|c|c|c|c|c|c|c|c|c|c|}
\hline \multirow{2}{*}{$\begin{array}{l}\text { Regiões } \\
\text { Metropolitanas }\end{array}$} & \multirow[t]{2}{*}{ Total } & \multicolumn{5}{|c|}{ Homens } & \multicolumn{5}{|c|}{ Mulheres } \\
\hline & & Total & $\begin{array}{c}10 \text { a } 17 \\
\text { anos }\end{array}$ & $\begin{array}{c}18 \text { a } 24 \\
\text { anos }\end{array}$ & $\begin{array}{c}25 \text { a } 39 \\
\text { anos }\end{array}$ & $\begin{array}{c}40 \text { anos } \\
\text { e mais }\end{array}$ & Total & $\begin{array}{c}10 \text { a } 17 \\
\text { anos }\end{array}$ & $\begin{array}{c}18 \text { a } 24 \\
\text { anos }\end{array}$ & $\begin{array}{c}25 \text { a } 39 \\
\text { anos }\end{array}$ & $\begin{array}{l}40 \text { anos } \\
\text { e mais }\end{array}$ \\
\hline \multicolumn{12}{|l|}{ São Paulo } \\
\hline 1989 & 8,7 & 7,5 & 22,7 & 10,4 & 5,1 & 3,3 & 10,6 & 28,0 & 13,9 & 7,9 & 3,9 \\
\hline 2000 & 17,6 & 15,0 & 42,1 & 21,9 & 10,8 & 10,6 & 20,9 & 52,0 & 29,1 & 17,9 & 11,6 \\
\hline \multicolumn{12}{|l|}{ Salvador } \\
\hline 1989 & 16,3 & 14,1 & 23,1 & 21,5 & 10,9 & 7,0 & 19,1 & 23,6 & 30,2 & 18,3 & 5,7 \\
\hline 2000 & 26,6 & & 54,9 & 43,8 & 26,3 & 15,5 & & 44,1 & 36,7 & 19,5 & 16,0 \\
\hline
\end{tabular}

Fonte: (1) Pesquisa de Emprego e Desemprego (PED), São Paulo e Salvador, microdados.

(2) DEDECCA, FERREIRA \& RODRIGUES (1990). 
A ampliação das dificuldades de inserção em ambos os mercados é encontrada seja para homens e mulheres, seja para os jovens e os mais idosos. Contudo, é inegável que o segmento populacional com 40 anos e mais continua tendo menores restriçóes, comparativamente aos segmentos mais jovens (Tabela 2). Os dados de desemprego sugerem que é justamente a população com maior experiência de trabalho, mas em geral com perfil educacional mais desfavorável, que foi menos prejudicada pelo crescimento do desemprego, indicando, desse modo, que a trajetória ocupacional passada constitui um passaporte de grande valia para se defender da possibilidade de desemprego. Como veremos mais à frente, a experiência de trabalho, na determinação da renda, é mais relevante que a condição de escolaridade. Esta observação nos remete ao objetivo deste ensaio, ou seja, à análise dos diferenciais de renda entre as duas Regióes Metropolitanas.

As diferenças básicas entre os dois mercados metropolitanos de trabalho estão sintetizadas na Tabela 3. Como se pode observar, o mercado de trabalho mostra-se mais vantajoso para os homens, tanto em São Paulo como em Salvador. O rendimento do trabalho, o rendimento total (que inclui outros rendimentos tais como aposentadorias e pensões), o nível de escolaridade, a experiência e a idade mostram-se mais elevados na Região Metropolitana de São Paulo que na de Salvador. Por outro lado, a estabilidade na ocupação é menor e o tempo dedicado ao trabalho é maior, de maneira que a rotatividade do trabalho e a quantidade de horas trabalhadas no mês apresentam-se menos fortes em Salvador.

Para a mulher, a Região Metropolitana de São Paulo mostra-se mais atrativa em relação à de Salvador, tanto em termos de rendimentos do trabalho quanto para os rendimentos totais. Isto decorre, de um lado, da maior escolaridade média e do maior esforço mensal de trabalho das trabalhadoras da RMSP, já que em termos de estabilidade e experiência, a região de Salvador aparece bem mais atrativa. Em termos de idade média, pode-se dizer que as duas regióes se equiparam, já que o teste de diferenças das médias não pôde detectar diferenças regionais significativas para essa variável.

É interessante notar que, para o trabalhador branco, a Região Metropolitana de Salvador mostra-se mais favorável para quase todas as variáveis. Percebe-se então que o rendimento médio do trabalho e total (inclusive outros rendimentos) bem como as médias da escolaridade, da estabilidade e da idade são todos mais elevados na RMS. Assim, os trabalhadores brancos da RMS, relativamente aos mesmos trabalhadores da RMSP, apresentam melhores resultados, apesar desta última região apresentar maiores níveis de experiência e de esforço mensal de trabalho. 
TABELA 3 - MÉDIA DA RENDA DO TRABALHO E DE ALGUNS ATRIBUTOS PESSOAIS POR SEXO, RAÇA E POSIÇÃO NA FAMÍLIA (CHEFE)

\begin{tabular}{|c|c|c|c|c|c|c|}
\hline \multirow[t]{2}{*}{ Atributo } & \multicolumn{2}{|c|}{ RMSP } & \multicolumn{2}{|c|}{ RMS } & \multicolumn{2}{|c|}{ Teste das médias } \\
\hline & Média & DP & Média & DP & Estatística t & Sig $t$ \\
\hline \multicolumn{7}{|l|}{ Homem } \\
\hline Renda total do trabalho & $1.068,82$ & $2.121,68$ & 663,58 & $1.111,99$ & 24,00 & 0,00 \\
\hline Renda Total & $1.112,50$ & $2.156,76$ & 691,35 & $1.155,76$ & 24,34 & 0,00 \\
\hline Escola & 8,55 & 4,25 & 8,08 & 4,07 & 11,23 & 0,00 \\
\hline Estabilidade & 5,33 & 7,19 & 5,57 & 7,42 & $-3,21$ & 0,00 \\
\hline Experiência & 20,77 & 13,94 & 20,51 & 13,03 & 1,93 & 0,05 \\
\hline Idade & 35,40 & 12,91 & 34,60 & 12,51 & 6,31 & 0,00 \\
\hline Esforço mensal & 194,53 & 75,48 & 187,54 & 78,88 & 8,87 & 0,00 \\
\hline \multicolumn{7}{|l|}{ Mulher } \\
\hline Renda total do trabalho & 635,09 & 921,26 & 416,21 & 732,60 & 22,80 & 0,00 \\
\hline Renda Total & 665,01 & 962,02 & 434,42 & 763,14 & 23,03 & 0,00 \\
\hline Escola & 9,01 & 4,31 & 8,76 & 4,23 & 5,23 & 0,00 \\
\hline Estabilidade & 4,54 & 6,11 & 5,46 & 7,29 & $-11,91$ & 0,00 \\
\hline Experiência & 19,47 & 13,83 & 19,76 & 12,80 & $-1,94$ & 0,00 \\
\hline Idade & 34,58 & 12,24 & 34,53 & 11,75 & 0,36 & 0,50 \\
\hline Esforço mensal & 160,44 & 75,45 & 158,95 & 81,38 & 1,67 & 0,10 \\
\hline \multicolumn{7}{|l|}{ Branco } \\
\hline Renda total do trabalho & $1.029,67$ & $1.996,57$ & $1.088,88$ & $1.576,58$ & $-40,02$ & 0,00 \\
\hline Renda Total & $1.075,76$ & $2.035,08$ & $1.147,55$ & $1.647,28$ & $-41,38$ & 0,00 \\
\hline Escola & 9,46 & 4,25 & 11,09 & 3,88 & $-63,71$ & 0,00 \\
\hline Estabilidade & 5,39 & 7,12 & 6,79 & 8,11 & $-22,68$ & 0,00 \\
\hline Experiência & 20,03 & 13,99 & 19,71 & 12,92 & 4,79 & 0,00 \\
\hline Idade & 35,55 & 12,79 & 36,81 & 12,56 & $-14,30$ & 0,00 \\
\hline Esforço mensal & 179,35 & 77,48 & 167,71 & 82,53 & 3,13 & 0,00 \\
\hline \multicolumn{7}{|l|}{ Negro } \\
\hline Renda total do trabalho & 525,87 & 582,37 & 449,45 & 760,97 & 10,32 & 0,00 \\
\hline Renda Total & 543,84 & 599,65 & 466,38 & 786,48 & 10,14 & 0,00 \\
\hline Escola & 6,98 & 3,81 & 7,90 & 4,01 & $-22,16$ & 0,00 \\
\hline Estabilidade & 4,03 & 5,67 & 5,29 & 7,19 & $-18,87$ & 0,00 \\
\hline Experiência & 20,68 & 13,69 & 20,24 & 12,93 & 3,04 & 0,00 \\
\hline Idade & 33,83 & 12,16 & 34,15 & 12,04 & $-2,55$ & 0,00 \\
\hline Esforço mensal & 181,72 & 76,92 & 175,69 & 81,01 & 7,26 & 0,00 \\
\hline \multicolumn{7}{|l|}{ Chefe } \\
\hline Renda total do trabalho & $1.181,78$ & $2.263,88$ & 757,10 & $1.198,42$ & 21,58 & 0,00 \\
\hline Renda Total & $1.246,38$ & $2.302,09$ & 800,79 & $1.251,84$ & 22,06 & 0,00 \\
\hline Escola & 8,18 & 4,53 & 8,11 & 4,36 & 1,45 & 0,25 \\
\hline Estabilidade & 6,55 & 7,88 & 7,34 & 8,42 & $-8,66$ & 0,00 \\
\hline Experiência & 26,28 & 12,90 & 26,11 & 12,24 & 1,25 & 0,25 \\
\hline Idade & 40,53 & 11,74 & 40,23 & 11,25 & 2,38 & 0,02 \\
\hline Esforço mensal & 194,67 & 78,55 & 188,17 & 81,24 & 7,27 & 0,00 \\
\hline
\end{tabular}

Fonte: Cálculos dos autores com base nos dados da PED-RMS e PED-RMSP. 
A situação dos negros também é interessante, pois eles ganham, em média, mais na RMSP, mesmo que os trabalhadores da RMS apresentem uma média de escolaridade e de estabilidade mais elevadas. O diferencial de rendimento do trabalho em favor da RMSP pode ser explicado, em parte, pela experiência e pelo esforço mensal de trabalho que são mais elevados na RMSP, relativamente à RMS. Quanto ao diferencial do rendimento total (inclusive outras rendas), uma explicação possível pode advir da maior formalidade das relações de trabalho presente na RMSP.

Os maiores rendimentos dos brancos da RMS, relativamente àqueles da RMSP, podem estar associados ao domínio social que essas pessoas exercem nessa região. Por outro lado, os rendimentos dos negros da RMSP, relativamente aos negros da RMS, devem estar influenciados pelo maior esforço dessas pessoas no mercado de trabalho, tendo em vista que os negros da RMSP detêm relativamente menor nível educacional.

Os chefes de família recebem relativamente mais na RMSP que na RMS. Estes resultados são também muito interessantes, já que pelo teste das médias a escolaridade e a experiência não apresentam diferenças significativas. Como a RMS mostra uma estabilidade mais elevada para essas pessoas, tem-se que o diferencial de rendimentos do trabalho em favor da RMSP encontra sua explicação quase que exclusivamente na maior quantidade de horas trabalhadas no mês.

A Tabela 4 permite observar que a renda média mostra-se, de maneira generalizada, mais elevada na Região Metropolitana de São Paulo que na de Salvador. Este fato é garantido pelo teste das médias. Isto acontece em todos os ramos de atividade econômica (exceto na agricultura, pesca e extração mineral, cujo peso econômico é insignificante nas duas regióes). Assim, os trabalhadores do ramo de serviços da RMSP ganham $66,0 \%$ a mais que os seus pares da RMS. O mesmo acontece para os do comércio de mercadorias, que recebem 52,0\% a mais; para os trabalhadores da construção civil, que auferem rendimentos médios $41,0 \%$ superiores; e para os trabalhadores da indústria, que ganham $29,0 \%$ a mais na RMSP.

Em todas as faixas de escolaridade, os rendimentos médios do trabalho são também superiores na Região Metropolitana de São Paulo. Os trabalhadores analfabetos funcionais (com até dois anos de estudos) recebem duas vezes mais na RMSP, enquanto que os que possuem estudos formais entre 3 e 8 anos recebem 92,0\% a mais, os que detêm estudos entre 9 e 11 anos ganham 37,0\% a mais e os que possuem mais de 12 anos de estudos recebem $29,0 \%$ a mais. Tem-se, portanto, uma relação inversa entre o diferencial do nível de escolaridade e o diferencial de rendimentos entre as regiões metropolitanas de São Paulo e de Salvador, ou seja, à medida que aumenta o grau de escolaridade do trabalhador, diminui o diferencial de rendimentos entre essas duas regióes. 
TABELA 4 - RENDA MÉDIA DO TRABALHO POR RAMO DE ATIVIDADE E FAIXAS DE ESCOLARIDADE E DE IDADE

\begin{tabular}{|c|c|c|c|c|c|c|}
\hline \multirow[t]{2}{*}{ Atributo } & \multicolumn{2}{|c|}{ RMSP } & \multicolumn{2}{|c|}{ RMS } & \multicolumn{2}{|c|}{ Teste das médias } \\
\hline & Média & $\mathrm{DP}$ & Média & $\mathrm{DP}$ & Estatística t & Sig $t$ \\
\hline \multicolumn{7}{|l|}{ Ramos de Atividade } \\
\hline Agric, pesca. E ext. mineral & 447,82 & 660,83 & 353,16 & $1.346,24$ & 0,83 & 0,50 \\
\hline Ind. transformação & 975,88 & $1.398,67$ & 756,54 & $1.179,48$ & 7,13 & 0,00 \\
\hline Construção civil & 646,74 & 909,31 & 458,62 & 735,39 & 6,62 & 0,00 \\
\hline Comércio de mercadorias & 640,14 & 899,98 & 422,42 & 829,40 & 12,41 & 0,00 \\
\hline Serviços & 927,15 & $1.998,00$ & 558,45 & 962,78 & 25,32 & 0,00 \\
\hline \multicolumn{7}{|l|}{ Faixas de Escolaridade } \\
\hline Analfabeto funcional & 384,14 & $2.873,00$ & 192,04 & $2.159,00$ & 0,92 & 0,00 \\
\hline Entre 3 e 8 anos & 518,92 & $18.472,00$ & 270,10 & $9.607,00$ & 0,30 & 0,50 \\
\hline Entre 9 e 11 anos & 738,94 & $12.761,00$ & 539,33 & $8.724,00$ & 0,37 & 0,00 \\
\hline 12 anos e mais & $2.066,43$ & $8.489,00$ & $1.602,38$ & $3.298,00$ & 2,77 & 0,01 \\
\hline \multicolumn{7}{|l|}{ Faixas de Idade } \\
\hline Até 17 anos & 170,33 & $1.917,00$ & 71,98 & $1.060,00$ & 0,50 & 0,50 \\
\hline Entre 18 e 25 & 490,56 & $10.355,00$ & 268,78 & $5.676,00$ & 0,39 & 0,50 \\
\hline Entre 26 e 59 & $1.055,99$ & $29.187,00$ & 662,96 & $16.396,00$ & 0,48 & 0,50 \\
\hline 60 anos e mais & 991,46 & $1.630,00$ & 769,61 & 710,00 & 5,54 & 0,00 \\
\hline
\end{tabular}

Fonte: Cálculos dos autores com base nos dados da PED-RMS e PED-RMSP.

O diferencial de rendimentos em favor dos trabalhadores da RMSP também se apresenta bastante forte quando se examinam as faixas de idade. Tem-se, então, que os adolescentes (até 17 anos) ganham 137,0\% a mais e os jovens (entre 18 e 25 anos) recebem $83,0 \%$ a mais na RMSP que na RMS. Seguindo o mesmo movimento, os trabalhadores que se encontram na idade economicamente mais ativa da vida (entre $26 \mathrm{e}$ 59 anos) ganham a mais 59,0\% na RMSP e os idosos (com 60 anos e mais) recebem a mais $29,0 \%$ nessa mesma região. Pode-se também confirmar que o diferencial de rendimentos entre as duas regiốes metropolitanas diminui à medida que a idade do trabalhador avança. No entanto, considerando a grande dimensão dos desvios padrões, pode-se dizer que as diferenças de rendimentos médios são menos significativas para a faixa de escolaridade que compóe o ensino fundamental e para as faixas etárias de "até 17 anos", "entre 18 e 25 anos" e "entre 26 e 59 anos", podendo-se mesmo dizer que, segundo o teste das médias, as rendas para essas faixas se igualam. 


\section{O MODELO E OS PROCEDEMINETOS ECONOMÉTRICOS UTILIZADOS}

A metodologia padrão de análise consiste na aplicação do instrumental econométrico sobre uma amostra com dados transversais ou em painel, tal como a maior parte dos estudos desta natureza. Para analisar a formação do rendimento dos trabalhadores dessas duas importantes regióes metropolitanas do País, considera-se, inicialmente, o seguinte modelo:

$$
\operatorname{Ln} w_{i}=\beta X_{i}+\gamma R_{j}+e_{i}
$$

onde $\mathrm{Ln} \mathrm{w}_{\mathrm{i}}$ é o logaritmo neperiano do rendimento do trabalhador $\mathrm{i} ; \mathrm{X}_{\mathrm{i}}$ é a matriz de atributos produtivos e não produtivos que pretensamente afeta o seu rendimento; $R_{j}$ é a dummy de intercepto que indexa a região; $\mathrm{e}_{\mathrm{i}}$ é o termo aleatório que representa os possíveis erros de medida da variável dependente, bem como todos os demais fatores não explicitados na equação, o qual admite-se ter distribuição de probabilidade normal com média zero e variância $\sigma^{2}$ e $\beta$ e $\gamma$ são os conjuntos de parâmetros a serem estimados, sendo que $\gamma$ representa a diferença dos interceptos das equações regionais consideradas. Deve-se ressaltar que, de acordo com o procedimento padrão, o diferencial dos interceptos é o elemento que permite estabelecer as diferenças regionais de rendimentos.

O ajustamento desse modelo, entretanto, apresenta alguns problemas. Um primeiro problema diz respeito ao método de estimação. Este problema fica mais evidente quando se desagrega a equação anterior em função das regiões $\left(\mathrm{R}_{\mathrm{j}}\right)$. Assim, o modelo anterior toma a seguinte forma:

$$
\mathrm{R}_{\mathrm{j}}=-(\alpha / \gamma)+(\mathrm{l} / \gamma) \ln \mathrm{w}_{\mathrm{i}}-(\beta / \gamma) \mathrm{X}_{\mathrm{i}}-(\mathrm{l} / \gamma) \mathrm{e}_{\mathrm{i}}
$$

As equações (1) e (2) são iguais sob o ponto de vista matemático e lógico, mas não são para a econometria. Na primeira equação, o rendimento está determinado pelos atributos $\mathrm{X}_{\mathrm{i}}$ e pelas regióes $\mathrm{R}_{\mathrm{j}}$, ou seja, dados os atributos e as regiões, pode-se encontrar os rendimentos, enquanto que a segunda equação estabelece que, para um determinado nível de rendimentos e dados níveis de atributos $\mathrm{X}_{\mathrm{i}}$, haverá uma demanda por trabalho, representada por probabilidades, nas diferentes regiões $R_{j}$. A grande diferença entre as duas equações é que, em verdade, elas não constituem funções, mas sim relações, de forma que o sentido de causalidade importa muito, mesmo que não se saiba exatamente se o seu sentido vai dos atributos $\mathrm{X}_{\mathrm{i}}$ e das regiões $\mathrm{R}_{\mathrm{j}}$ aos salários ou dos salários e atributos $X_{i}$ às regiões $R_{j}$.

Assim, desde que o método dos mínimos quadrados permite o cálculo de funções e não de relações, tem-se que o uso da primeira ou da segunda equação apresentará resultados diferentes quanto aos sinais, além da possibilidade de se obter valores para a 
probabilidade $\mathrm{R}_{\mathrm{j}}$ maiores que um ou menores que zero. Esses fatos póem em evidência consequiências cruciais na interpretação dos resultados. Para manter a probabilidade $R_{j}$ no intervalo $[0,1]$, deixa-se de utilizar o método dos mínimos quadrados e passa-se a estimar a equação (2) por meio de modelos probabilísticos do tipo probit e logit. A função probit se enquadra perfeitamente bem a essa necessidade. Esta função encontra-se relacionada com a distribuição de probabilidade normal padronizada, permitindo, portanto, a consideração de coeficientes angulares variáveis, isto é, não constantes, diferentemente da equação (1). Vale lembrar que a função probit pode ser especificada por:

$$
f(z)=P[Z \leq z]=\int_{-\infty}^{z}\left[1 /(2 \pi)^{1 / 2}\right] e \quad d z
$$

Um segundo problema diz respeito a um possível viés de seleção presente na amostra. Normalmente, regressa-se o salário em função de variáveis explicativas $\left(\mathrm{X}_{\mathrm{i}}\right)$ das pessoas ocupadas, deixando-se de fora os desempregados e os inativos. Isto se dá em virtude dos desempregados e dos inativos não possuírem empregos remunerados, provavelmente em decorrência de se apresentarem ao mercado com salários de reserva mais elevados que os salários que o mercado thes oferece. Por isso mesmo, não se pode observar o que se passa com os salários dos desempregados e dos inativos, dado que por definição eles não os possuem, mas a amostra utilizada (referente apenas aos ocupados) pode não ser, necessariamente, representativa de toda a população, havendo, por conseguinte, um viés de seleção, que conduzirá inexoravelmente a conclusões falsas. Para esse tipo de problema, Heckman (1979) propõe uma solução no mínimo engenhosa, que consiste em regressar, inicialmente, uma equação análoga à (2), por meio do modelo probit, para observar qual a probabilidade de uma pessoa participar do mercado de trabalho, seja esta pessoa ocupada, desempregada ou inativa. Em seguida, com o uso dos estimadores encontrados, calcula-se uma nova variável, denominada de função inversa de Mills, com a qual volta-se à regressão da equação (1) adicionada dessa nova variável.

Após a estimação das equações de rendimentos do trabalho, com a incorporação do procedimento de Heckman, aplica-se a decomposição de Oaxaca (1973). Esta decomposição consiste em utilizar, para cada grupo de trabalhadores, duas regressões, uma para cada região, em vez de apenas uma. A primeira das regressóes considera um grupo específico de trabalhadores relativo a uma das duas regióes, por exemplo, homens de São Paulo, enquanto que na segunda equação considera-se o grupo de trabalhadores da outra região, ou seja, homens de Salvador, e assim sucessivamente para os demais grupos de trabalhadores analisados (mulheres, brancos e negros).

Diante do exposto, pode-se estabelecer a seguinte seqüência para os procedimentos mencionados, os quais dar-se-ão em três etapas: 
1. Estima-se uma equação de participação para cada região $r$ de um mesmo grupo $j$ de pessoas, utilizando-se o modelo probit, que permitirá obter, por meio da determinação da razão inversa de Mills, uma nova variável. Isto é, as equações abaixo serão estimadas, de maneira independente, para as Regiões Metropolitanas de São Paulo e de Salvador, respectivamente, para cada grupo de trabalhadores considerado, ou seja, homens $(\mathrm{H})$, mulheres $(\mathrm{M})$, brancos $(\mathrm{B})$ e negros $(\mathrm{N})$ :

$$
\mathrm{P}_{\mathrm{jr}}=\alpha_{\mathrm{jr}}+\beta_{\mathrm{jr}} \mathrm{X}_{\mathrm{iir}}+\mathrm{e}_{\mathrm{ijr}} \quad(\mathrm{r}=1,2)
$$

onde $\mathrm{j}$ indexa homens, mulheres, błancos e negros; $r$ indexa a região (ou seja, RMSP para a região 1 e RMS para à régião 2). Deve-se ressaltar que a variável $P_{j r}$ representa a probabilidade dos indivíduos do grupo j, na região $r$, encontrarem-se ocupados, de maneira que essa variável é dicotômica e tomará o valor unitário quando a pessoa estiver ocupada e zero quando a mesma estiver desempregada ou inativa. Assim, quando $\mathrm{P}=1$, significa dizer que o indivíduo compatibilizou seu salário de reserva com o salário oferecido pelo mercado e, por isso mesmo, aceitou exercer uma atividade econômica remunerada. Por outro lado, quando $\mathrm{P}=0$, é porque os salários de reserva, de alguma forma, encontram-se acima dos salários oferecidos no mercado, de maneira que o indivíduo prefere manter-se fora do mercado de trabalho. Vale lembrar que $\beta_{\mathrm{jr}}$ mede o efeito de uma mudança nos respectivos vetores de atributos produtivos e não produtivos das pessoas do grupo j sobre a decisão dessas mesmas pessoas aceitarem exercer uma ocupação remunerada na região $r$.

2. Calcula-se a razão inversa de Mills para cada região $r$ do conjunto analisado de pessoas $\mathrm{j}$.

3. Em seguida, introduz-se a razão inversa de Mills nas equaçôes de rendimento para corrigir possíveis problemas de viés de seleção amostral, que decorrem do fato de serem tomados apenas os trabalhadores ocupados e com rendimentos positivos. Este procedimento permitirá obter estimadores consistentes para os parâmetros das equações de salários. Assim, estima-se, por meio do método dos mínimos quadrados, uma equação de (logaritmo neperiano dos) rendimentos para cada região $\mathrm{r}$ em cada conjunto analisado de pessoas $j$, ou seja, primeiro para gênero:

$$
\ln w_{j r}=\alpha_{j r}+\beta_{j r} X_{i j r}+\lambda_{j r}+e_{i j r}
$$

onde $\ln \mathrm{w}_{\mathrm{jr}}$ é o logaritmo neperiano dos salários de cada grupo j na região $\mathrm{r}, \mathrm{X}_{\mathrm{ijr}}$ é o vetor de características do trabalho e atributos pessoais produtivos e não produtivos do grupo j na região $\mathrm{r}, \lambda$ é a razão inversa de Mills e $e_{\mathrm{i}}$ é o erro, o qual se 
admite ser normalmente distribuído com média zero e desvio padrão igual à unidade.

4. Procede-se à decomposição de Oaxaca a partir da seguinte equação:

$$
\mathrm{Ln} \mathrm{w}_{\mathrm{jr}}=\alpha_{\mathrm{jr}}+\sum \beta_{\mathrm{ijr}} \chi_{\mathrm{ijr}}+\mathrm{e}_{\mathrm{ijr}} \quad(\mathrm{r}=1,2)
$$

onde $\mathrm{Ln} \mathrm{w}_{\mathrm{jr}}$ representa o logaritmo natural do valor esperado do rendimento; $\chi_{\mathrm{ijr}}$ é o vetor de características do trabalho e atributos pessoais dos trabalhadores ${ }^{1}$ avaliadas nos pontos médios de cada região $r$ e em cada grupo j. Em seguida avalia-se a diferença entre essas duas equações nos pontos médios das respectivas variáveis, adicionando-se e subtraindo-se o termo $\sum \beta_{\mathrm{ij} 1} \chi_{\mathrm{ij} 2}$, de maneira a não haver alteração na igualdade, donde chega-se à seguinte expressão:

$$
\bar{\sigma}_{\mathrm{j} 1}-\bar{\varpi}_{\mathrm{j} 2}=\left(\alpha_{\mathrm{j} 1}-\alpha_{\mathrm{j} 2}\right)+\sum \chi_{\mathrm{ij} 2}\left(\beta_{\mathrm{ij} 1}-\beta_{\mathrm{ij} 2}\right)+\sum \beta_{\mathrm{ij} 1}\left(\chi_{\mathrm{ij} 1}-\chi_{\mathrm{ij} 2}\right)
$$

em que $\varpi_{j 1}-\varpi_{j 2}$ representa a diferença entre os logaritmos dos salários médios dos trabalhadores nessas duas regiões em cada grupo $\mathrm{j}$.

O primeiro termo, $\left(\alpha_{j 1}-\alpha_{j 2}\right)$, que constitui a diferença dos interceptos, mede os diferenciais de rendimentos devido às características específicas dos trabalhadores de cada região, em cada grupo $\mathrm{j}$, independentemente das características do trabalho e de seus atributos produtivos. Na hipótese desse termo apresentar sinal positivo, isto significa que o trabalhador na região 1 é mais bem remunerado em sua atividade que na região 2 , independentemente da distribuição dos atributos pessoais dos trabalhadores em cada região.

O segundo termo, $\sum \chi_{\mathrm{ij} 2}\left(\beta_{\mathrm{ij} 1}-\beta_{\mathrm{ij} 2}\right)$, compõe também uma medida de diferenciação de rendimentos entre regiões que independe das respectivas características do trabalho e atributos pessoais (produtivos e não produtivos). Esse termo pode estar representando uma valoração diferenciada desses mesmos atributos entre essas duas regiôes. O sinal positivo desse termo evidencia uma maior valoração dos atributos pessoais para a região 1 em detrimento da região 2, que se verifica de maneira independente da dotação dos atributos pessoais. Esse segundo termo pode ser eventualmente adicionado ao primeiro, compondo uma medida para a remuneração não condicionada às características do trabalho e dos atributos pessoais dos trabalhadores em cada região.

Finalmente, o terceiro termo, $\Sigma \beta_{\mathrm{ij} 1}\left(\chi_{\mathrm{ij} 1}-\chi_{\mathrm{ij} 2}\right)$, representa os diferenciais de rendimentos do trabalho relativos à diferenciação na dotação dos atributos pessoais dos trabalha-

1 Tendo sido aplicado o procedimento de Heckman, $\chi_{\mathrm{ijr}}$ incorpora a razão inversa de Mills $(\lambda)$. 
dores em cada região. As regióes mais bem dotadas nestes atributos, justificadamente, assegurarão remunerações mais elevadas para seus respectivos trabalhadores.

\section{OS RESULTADOS}

Para entender melhor os diferenciais regionais de rendimentos, independentemente daquilo que é perfeitamente justificado por diferentes características do trabalho e distintas distribuições de atributos dos trabalhadores, procedeu-se a uma avaliação seletiva, a partir de uma amostra retirada das bases PED das regióes metropolitanas de São Paulo e de Salvador, para o ano 2000. Essa amostra considerou um total de 191.393 indivíduos, sendo que 118.967 são da RMSP e 72.426 da RMS. Estabeleceram-se, então, cortes para as pessoas com menos de 10 anos e mais de 65 anos de idade, de maneira que a amostra total foi reduzida para 115.631 pessoas, das quais 70.556 estão inseridas na região metropolitana de São Paulo e 45.075 na região metropolitana de Salvador. Assim, após os cortes, a proporção das regiốes metropolitanas de São Paulo e de Salvador, na amostra, correspondeu a $61,0 \%$ e $39,0 \%$, respectivamente. Deve-se ressaltar, entretanto, que as observações consideradas nas regressões dos rendimentos do trabalho mostram-se ainda menores, tendo em vista que apenas os ocupados com rendimentos positivos são considerados, não se incorporando, portanto, os desempregados e os inativos. Esta consideração reduziu a amostra para 36.748 pessoas ocupadas da RMSP e 21.585 pessoas ocupadas da RMS, modificando a proporção da RMSP e da RMS na amostra para $63,0 \%$ e $37,0 \%$, respectivamente.

Para o cálculo das equações de participação das pessoas no mercado de trabalho foram consideradas as seguintes variáveis:

1. rdamefam - renda média da família (medida em reais).

2. rendout - outros rendimentos não provenientes do trabalho, tais como aluguéis, aposentadorias, pensôes, seguro-desemprego, bicos e trabalhos ocasionais (medida em reais).

3. escola - escolaridade (medida em anos).

4. exper - experiência (medida em anos).

5. expqua - experiência ao quadrado.

6. escexp - variável multiplicativa da escolaridade x experiência.

7. chefe - chefe de família (chefe de família $=1$ e demais membros $=0$ ). 
8. cônjuge - cônjuge (cônjuge $=1$ e demais membros $=0$ ).

9. dmfifam - existência de filhos na família $=1$ e caso contrário $=0$.

Para a estimativa das equaçôes de rendimentos do trabalho das pessoas ocupadas nas duas regiốes metropolitanas foram adotadas, além da variável dependente "logaritmo neperiano do rendimento total do trabalho" (rendimento do trabalho principal mais rendimento do trabalho secundário, quando for o caso), as seguintes variáveis independentes:

10. escola - escolaridade (medida em anos).

11. estab - estabilidade na ocupação (medida em anos).

12. exper - experiência (medida em anos).

13. experqua - experiência ao quadrado.

14. escexp - escolaridade-experiência.

15. assala - assalariado (assalariado com e sem comissão $=1$ e demais posiçóes $=0$ ).

16. autonom - trabalhador autônomo (conta-própria $=1$ e demais posições $=0$ ).

\subsection{Resultados das Equações de Participação}

Uma inspeção das Tabelas 5 e 6 permite observar que, segundo o sexo, todos os parâmetros estimados, exceto um, foram estatisticamente significativos e diferentes de zero, resultado este garantido pela estatística Wald. A exceção detectada foi para o homem da região metropolitana de São Paulo, quando na condição de cônjuge, que foi significativo a apenas $21,0 \%$. Este fato não causa estranheza, já que esta variável tem implicaçốes maiores apenas para as mulheres, dado que estas costumam sair, mais facilmente, do mercado de trabalho quando se casam ou quando vão ter filhos.

Na seqüência, apresentam-se os principais resultados obtidos nas equações de participação, os quais, por uma questão de didática, seguem a ordem de visualização nas tabelas, quando o forte seria apresentá-los pela ordem de importância apontada no teste de Wald, de maneira que as respectivas significâncias dos resultados podem ser avaliadas nas colunas referentes a este teste.

Dessa forma, os resultados das Tabelas 5 e 6 revelam que a renda média da família foi estatisticamente significativa e positivamente correlacionada com a propensão do trabalhador engajar-se em alguma ocupação no mercado de trabalho. Isto acontece tanto 
para homens quanto para mulheres, bem como para brancos e negros das duas regióes metropolitanas. De certa forma, este resultado não surpreende, tendo em vista que no bojo da renda familiar está incluído o rendimento do próprio trabalhador. Desta forma, o efeito substituição tende a suplantar o efeito renda, de modo que a correlação entre a renda média da família e a propensão ao trabalho apresenta-se positiva. $\mathrm{O}$ fato de o efeito substituição ter suplantado o efeito renda estimula uma participação na força de trabalho até mesmo para manter o padrão de vida já alcançado pela família. Assim, quanto maior essa renda mais as pessoas tendem a se apresentar no mercado de trabalho.

O controle por meio da variável outras rendas (a qual incorpora outras rendas pessoais, tais como aposentadoria, pensão, seguro-desemprego, entre outras) mostrou-se, para as duas regiões metropolitanas estudadas, estatisticamente significativo e negativamente correlacionado com a possibilidade de o indivíduo estar ou não ocupado. Isto significa que quanto maior for o nível dessas rendas, menor será a probabilidade de a pessoa estar de alguma forma ocupada no mercado de trabalho. Este resultado revela que esse tipo de rendimento (exógeno ao mercado de trabalho) está negativamente correlacionado com o rendimento cuja fonte é o trabalho (renda endógena).

As Tabelas 5 e 6 também mostram que níveis mais elevados de escolaridade encontramse associados a uma maior participação dos homens, das mulheres, dos brancos e dos negros em ambos os mercados metropolitanos de trabalho. Esta relação pode estar refletindo condições menos desfavoráveis de inserção para trabalhadores com maior nível educacional em uma situação de forte constrangimento nos dois mercados de trabalho.

Ainda analisando as Tabelas 5 e 6 pode-se observar que a experiência das pessoas apresenta uma relação direta com a probabilidade de o indivíduo encontrar-se ocupado no mercado de trabalho. Este resultado se mostrou verdadeiro para todos os agrupamentos de pessoas nas duas regióes estudadas. Ainda com o auxílio das Tabelas 5 e 6 percebe-se que a implicação da variável experiência ao quadrado na probabilidade das pessoas encontrarem-se ocupadas foi estabelecida por meio de uma relação inversa. Tem-se, portanto, que um aumento da experiência do trabalhador induz uma maior participação no mercado de trabalho, contudo a taxas decrescentes. Este resultado foi garantido para todos os agrupamentos de trabalhadores ocupados, tanto na região metropolitana de São Paulo quanto na de Salvador.

Em princípio, a interação entre a escolaridade e a experiência deveria potencializar a probabilidade das pessoas estarem ocupadas. No entanto, a correlação desta variável multiplicativa com a probabilidade de a pessoa estar na força de trabalho se mostrou negativa para os quatro agrupamentos de trabalhadores considerados e em ambas as regiões metropolitanas analisadas. 
TABELA 5 - EQUAÇÕES DE PARTICIPAÇÃO POR SEXO

\begin{tabular}{|c|c|c|c|c|c|c|c|c|}
\hline \multirow[t]{2}{*}{ Variáveis } & \multicolumn{4}{|c|}{ RMSP } & \multicolumn{4}{|c|}{ RMS } \\
\hline & B & DP & Wald & Sig. & B & DP & Wald & Sig. \\
\hline \multicolumn{9}{|l|}{ Homem } \\
\hline Constante & 0,761 & 0,062 & 148,93 & 0,00 & 1,388 & 0,072 & 371,04 & 0,00 \\
\hline Rdamefam & 0,0008026 & 0,000 & 811,10 & 0,00 & 0,001029 & 0,000 & 480,39 & 0,00 \\
\hline Rendout & $-0,001317$ & 0,000 & $1.165,27$ & 0,00 & $-0,001532$ & 0,000 & 659,15 & 0,00 \\
\hline Escola & 0,0592 & 0,005 & 128,57 & 0,00 & 0,07207 & 0,006 & 134,52 & 0,00 \\
\hline Exper & 0,06238 & 0,004 & 257,32 & 0,00 & 0,08434 & 0,005 & 324,86 & 0,00 \\
\hline Expqua & $-0,001184$ & 0,000 & 496,87 & 0,00 & $-0,001488$ & 0,000 & 500,88 & 0,00 \\
\hline EscExp & $-0,001521$ & 0,000 & 61,98 & 0,00 & $-0,001401$ & 0,000 & 34,83 & 0,00 \\
\hline Chefe & 0,654 & 0,022 & 847,89 & 0,00 & 0,628 & 0,026 & 570,13 & 0,00 \\
\hline Cônjuge & 0,08585 & 0,069 & 1,57 & 0,21 & 0,207 & 0,087 & 5,70 & 0,02 \\
\hline \multirow[t]{2}{*}{ Dmfifam } & 0,162 & 0,022 & 55,80 & 0,00 & 0,169 & 0,026 & 42,32 & 0,00 \\
\hline & Teste da RV & 28.576 & No. Obs. & 33.543 & Teste da RV & 21.390 & No. Obs. & 20.669 \\
\hline \multicolumn{9}{|l|}{ Mulher } \\
\hline Constante & 1,457 & 0,057 & 642,92 & 0,00 & 1,999 & 0,068 & 856,70 & 0,00 \\
\hline Rdamefam & 0,0002656 & 0,000 & 325,44 & 0,00 & 0,0007296 & 0,000 & 581,01 & 0,00 \\
\hline Rendout & $-0,0007646$ & 0,000 & 331,05 & 0,00 & $-0,001391$ & 0,000 & 406,83 & 0,00 \\
\hline Escola & 0,141 & 0,005 & 948,66 & 0,00 & 0,141 & 0,006 & 634,08 & 0,00 \\
\hline Exper & 0,118 & 0,004 & $1.141,73$ & 0,00 & 0,136 & 0,004 & $1.024,12$ & 0,00 \\
\hline Expqua & $-0,001854$ & 0,000 & $1.453,71$ & 0,00 & $-0,002087$ & 0,000 & $1.184,39$ & 0,00 \\
\hline EscExp & $-0,004107$ & 0,000 & 548,39 & 0,00 & $-0,003986$ & 0,000 & 352,46 & 0,00 \\
\hline Chefe & 0,185 & 0,025 & 54,04 & 0,00 & 0,173 & 0,029 & 35,07 & 0,00 \\
\hline Cônjuge & $-0,531$ & 0,019 & 795,22 & 0,00 & $-0,329$ & 0,022 & 214,20 & 0,00 \\
\hline \multirow[t]{2}{*}{ Dmfifam } & $-0,207$ & 0,019 & 116,31 & 0,00 & $-0,196$ & 0,024 & 67,38 & 0,00 \\
\hline & Teste da RV & 42.521 & No. Obs. & 37.013 & Teste da RV & 28.975 & No. Obs. & 24.406 \\
\hline
\end{tabular}

Comparando esse resultado com aqueles obtidos para cada uma das variáveis é possível considerar que a experiência de trabalho tenha mais relevância, ao menos até o presente momento, que o nível de escolaridade para a determinação dos rendimentos. Os próprios resultados contidos na Tabela 3 referendam este argumento, ao apontar, e em especial para as mulheres, uma maior importância da experiência de trabalho vis-àd-vis à condição de escolaridade. Ademais, esse ponto de vista é convergente com aquele apontado quando foram analisadas as taxas de desemprego segundo idade, e se observou que estas continuam sendo mais baixas para a população com 40 anos e mais, que, 
em geral, possui uma situação de escolaridade relativamente mais desfavorável. Este resultado é compatível com várias formulações teóricas sobre mercado de trabalho, que defendem, em face da escassez de posto de trabalho, que os atributos pessoais passam a ser instrumentos importantes para a competição por uma ocupação. A ausência de dados para o início da década impede que se cheque adequadamente essa hipótese, apesar dos próprios dados utilizados the darem respaldo.

Ainda baseado nos resultados presentes nas Tabelas 5 e 6 , pode-se observar que os chefes de família apresentaram uma relação positiva com a probabilidade de estarem ocupados, independentemente do sexo e da raça, nas duas regióes metropolitanas consideradas. É possível que a pressão exercida pelos chefes decorra da sua responsabilidade como maior provedor dos elementos materiais da família. Vale aqui apresentar uma ressalva quando se trata da chefia feminina, que está cada vez mais presente na nossa sociedade. Mesmo assim, pode-se dizer que a mulher, chefe de família, se diferencia das demais mulheres e mantém um comportamento idêntico ao do homem chefe. É provável que essa situação seja também explicada pelos chefes possuírem, em geral, maior experiência de trabalho.

A condição de cônjuge, que a princípio deveria afetar de forma negativa apenas as mulheres, já que estas assumem, mais freqüentemente, papel secundário no provimento familiar de modo mais recorrente, também se mostrou negativamente relacionada aos brancos e negros. Apenas o cônjuge masculino apresentou-se probabilisticamente mais inclinado a procurar uma ocupação no mercado de trabalho. Observou-se um padrão idêntico a este resultado para as regiões metropolitanas de São Paulo e de Salvador.

Por fim, as Tabelas 5 e 6 apontam que a existência de filhos na família impóe resultados bastante diferenciados. Assim, os homens com filhos das duas regióes metropolitanas, como era de se esperar, ficam mais propensos à ocupação, enquanto as mulheres com filhos, também de maneira esperada, mostram-se menos inclinadas ao mercado de trabalho. Por outro lado, tem-se que os indivíduos brancos da região metropolitana de São Paulo tendem a se ausentar do mercado de trabalho quando possuem filhos, enquanto que estas pessoas se mostram mais presentes no mercado de trabalho na região metropolitana de Salvador. Os negros com filhos, por sua vez, apresentam uma relação negativa com o mercado de trabalho, ou seja, à medida que essas pessoas têm filhos, probabilisticamente se mostram menos inclinados a exercer alguma atividade ocupacional. Assim, pode-se avançar que a presença de filhos na família, efetivamente, restringe a capacidade de as pessoas se apresentarem no mercado de trabalho, notadamente as mulheres, as quais, tradicionalmente, são as maiores responsáveis pela criação dos filhos, ficando, muitas vezes, obrigadas a se retirarem do mercado de trabalho, principalmente nos dois primeiros anos de vida dos mesmos, diante das necessidades de sua presença no lar. 
TABELA 6 - EQUAÇÕES DE PARTICIPAÇÃO POR RAÇA

\begin{tabular}{|c|c|c|c|c|c|c|c|c|}
\hline \multirow[t]{2}{*}{ Variáveis } & \multicolumn{4}{|c|}{ RMSP } & \multicolumn{4}{|c|}{ RMS } \\
\hline & B & $\mathrm{DP}$ & Wald & Sig & B & $\mathrm{DP}$ & Wald & Sig \\
\hline \multicolumn{9}{|l|}{ Branco } \\
\hline Constante & 1,057 & 0,051 & 433,76 & 0,00 & 2,277 & 0,135 & 283,41 & 0,00 \\
\hline Rdamefam & 0,0003275 & 0,000 & 624,02 & 0,00 & 0,0004569 & 0,000 & 165,36 & 0,00 \\
\hline Rendout & $-0,0008473$ & 0,000 & 843,27 & 0,00 & $-0,0007795$ & 0,000 & 161,26 & 0,00 \\
\hline Escola & 0,103 & 0,004 & 657,23 & 0,00 & 0,145 & 0,011 & 189,34 & 0,00 \\
\hline Exper & 0,09137 & 0,003 & 895,36 & 0,00 & 0,137 & 0,008 & 287,26 & 0,00 \\
\hline Expqua & $-0,001577$ & 0,000 & $1.428,61$ & 0,00 & $-0,002235$ & 0,000 & 387,13 & 0,00 \\
\hline EscExp & $-0,0028$ & 0,000 & 355,74 & 0,00 & $-0,003754$ & 0,000 & 97,16 & 0,00 \\
\hline Chefe & 0,544 & 0,019 & 803,84 & 0,00 & 0,642 & 0,053 & 148,75 & 0,00 \\
\hline Cônjuge & $-0,594$ & 0,018 & $1.068,59$ & 0,00 & $-0,289$ & 0,051 & 32,46 & 0,00 \\
\hline \multirow[t]{2}{*}{ Dmfifam } & $-0,02639$ & 0,017 & 2,39 & 0,12 & 0,07184 & 0,044 & 2,71 & 0,10 \\
\hline & Teste da RV & 49.739 & No. Obs. & 49.817 & Teste da RV & 7.043 & No. Obs. & 6.589 \\
\hline \multicolumn{9}{|l|}{ Negro } \\
\hline Constante & 1,063 & 0,080 & 176,23 & 0,00 & 1,558 & 0,054 & 832,90 & 0,00 \\
\hline Rdamefam & 0,001486 & 0,000 & 794,00 & 0,00 & 0,001166 & 0,000 & $1.088,18$ & 0,00 \\
\hline Rendout & $-0,002544$ & 0,000 & 881,61 & 0,00 & $-0,002129$ & 0,000 & $1.185,64$ & 0,00 \\
\hline Escola & 0,07721 & 0,007 & 118,50 & 0,00 & 0,09404 & 0,005 & 416,81 & 0,00 \\
\hline Exper & 0,07677 & 0,005 & 227,05 & 0,00 & 0,103 & 0,003 & 902,85 & 0,00 \\
\hline Expqua & $-0,001287$ & 0,000 & 328,23 & 0,00 & $-0,001698$ & 0,000 & $1.206,98$ & 0,00 \\
\hline EscExp & $-0,001886$ & 0,000 & 42,36 & 0,00 & $-0,002315$ & 0,000 & 167,00 & 0,00 \\
\hline Chefe & 0,576 & 0,029 & 406,51 & 0,00 & 0,502 & 0,020 & 621,38 & 0,00 \\
\hline Cônjuge & $-0,562$ & 0,027 & 418,22 & 0,00 & $-0,359$ & 0,020 & 320,80 & 0,00 \\
\hline \multirow[t]{2}{*}{ Dmfifam } & $-0,01734$ & 0,027 & 0,41 & 0,52 & $-0,03504$ & 0,019 & 3,29 & 0,07 \\
\hline & Teste da RV & 21.901 & No. Obs. & 20.736 & Teste da RV & 43.094 & No. Obs. & 38.468 \\
\hline
\end{tabular}

\subsection{Resultados das Equações de Rendimentos}

Os resultados contidos na Tabela 7 permitem afirmar que, para análises com dados em painéis, o poder de explicação das regressóes mostrou-se razoavelmente elevado, na 
medida em que os $\mathrm{R}^{2}$ variaram entre 0,44 (negros de São Paulo) e 0,60 (homens de Salvador). Os testes F também foram satisfatórios, tendo flutuado entre 628 (brancos de Salvador) e 3.897 (brancos de São Paulo). Apenas as variáveis "experiência ao quadrado" e "escolaridade x experiência" apresentaram baixos níveis de significância em algumas regressões, como pode ser visualizado na referida tabela. Mesmo assim, essas variáveis foram mantidas para que se pudesse alcançar uma homogeneização analítica, utilizando-se das mesmas variáveis em todas as regressóes, permitindo, com isso, uma maior comparabilidade entre os resultados.

A escolaridade, proxy da qualificação e, portanto, que pode estar associada a uma produtividade mais elevada do trabalho, apresentou sinal positivo para todos os agrupamentos de trabalhadores analisados de ambas as regiões metropolitanas consideradas. Assim, quanto maior o nível de escolaridade alcançado pelo indivíduo, maior também será a possibilidade dele auferir rendimentos mais elevados no mercado de trabalho.

É lógico que essa determinação deve ser tomada de maneira cautelosa, em razão de a escolaridade sinalizar, no Brasil, statu quo bastante distintos, não permitindo, desse modo, uma aderência mais adequada à noção de qualificação. Isto induz, inclusive, a uma grande variância de escolaridade no interior de grupos ocupacionais com níveis de rendimentos mais homogêneos. Essa particular situação foi apontada em trabalho clássico dos anos 70, que mostrou ser inadequada a relação direta entre baixo nível de escolaridade e concentração da distribuição de renda. (MALAN, 1978).

Apesar dos questionamentos quanto à representatividade dessa variável, ela pode ser tomada como medida indicativa dos diferenciais de produtividade. É quase um consenso a afirmação de que a elevação dos níveis de rendimentos e uma maior competitividade futuras dependem de uma melhora dos níveis de escolaridade. Esta visão é respaldada no resultado obtido pela Coréia nesses últimos 20 anos. Ao aceitar este papel da escolaridade para o crescimento incorpora-se, mesmo que de modo implícito, sua vinculação com a produtividade. O que não se justifica, e isto é apontado pelos resultados da variável experiência de trabalho, é fazer uma identidade simples entre educação, produtividade e rendimento. Este círculo somente poderá ser virtuoso se houver crescimento da economia, com aumento do nível de emprego, de forma a permitir que a relação entre educação e produtividade se traduza em maiores níveis de rendimento.

Essa relação poderá ser ainda mais virtuosa se permitir uma maior estabilidade ocupacional. Como os resultados apontam, a estabilidade, que representa o tempo que o indivíduo se encontra na ocupação atual, também foi positiva em todas as regressóes de rendimentos. Embora esta variável tenha sido bastante útil para a formação do rendimento do trabalhador, ela pode apresentar dois efeitos que caminham em sentidos contrários. Por um lado, as pessoas que permanecem mais tempo em uma mesma ocupação, costumam também encontrar maiores dificuldades de reinserção no mercado de trabalho quando enfrentam períodos de desemprego. Desta forma, os indivídu- 
os, diante de uma situação de desemprego elevado, podem preferir uma certa estabilidade ocupacional em troca de menores rendimentos do trabalho. Esta hipótese encontra um embasamento na teoria dos contratos implícitos, em que os trabalhadores aceitam salários abaixo de suas respectivas produtividades marginais, tendo em vista uma garantia de perenidade no emprego. Por outro lado, esta mesma estabilidade significa dizer que a ocupação encontra-se associada a investimentos de formação e treinamento realizados pelas empresas, que, por serem indissociáveis da pessoa que a ocupa, acaba favorecendo a estabilidade, bem como o sistema de qualificação em geral. A maior estabilidade na ocupação favorece a qualificação do ocupado, de maneira que o empregador preferirá despedi-lo somente quando não houver outra alternativa, logo, por este ângulo, se fortalece a hipótese de que haverá uma relação direta entre estabilidade e o rendimento do trabalhador. ${ }^{2}$

A variável experiência, obtida pela diferença entre a idade, o tempo de escolaridade e seis anos relativos à idade pré-escolar da pessoa, foi negativa apenas para os brancos da região metropolitana de Salvador, sendo, portanto, positiva nas demais regressóes. Tem-se, assim, que quanto maior a experiência, maior também será o rendimento auferido pelo indivíduo. Esta variável tem sido também questionada pelo menos em dois aspectos. O primeiro se reporta às mulheres, as quais entram e saem do mercado de trabalho inúmeras vezes ao longo da vida economicamente ativa, além de estarem mais presentes nos trabalhos em tempo parcial. O segundo alcança os homens, cuja exposição ao desemprego tem aumentado nos últimos vinte anos. Assim, nos dois casos, essa variável pode apresentar uma medida sobreestimada da experiência adquirida ao longo da vida ocupacional do indivíduo.

A experiência ao quadrado, que mede a taxa de variação do salário quando a experiência se eleva, foi positiva para os homens, brancos e negros de Salvador, bem como para os brancos de São Paulo, sendo negativa para as demais regressões. Esperava-se, de maneira generalizada, um sinal negativo para esta variável, ou seja, à medida que a experiência aumenta, deveria haver uma tendência de crescimento da renda, mas a taxas decrescentes, fato este que não se confirmou nas regressões acima mencionadas.

A variável multiplicativa da escolaridade x experiência, a princípio dinamiza a capacitação da pessoa, tanto para encontrar uma ocupação como para auferir rendimentos mais elevados do trabalho. Assim, quanto maior a educação formal e a experiência mais competitiva se torna esta pessoa, estando, assim, mais apta a conseguir melhores remuneraçôes no mercado de trabalho, impondo, portanto, uma relação direta com esses mesmos rendimentos. Mesmo assim, essa variável mostrou-se negativa para os homens e mulheres de Salvador, bem como para as mulheres de São Paulo.

2 O mesmo argumento pode ser utilizado para o assalariado formal de grandes empresas, já que ele pode estar vinculado a um mercado interno. Por isso mesmo, estabilidade pode se transformar em sinônimo de rendimentos mais elevados. 
TABELA 7 - EQUAÇÕES DE RENDIMENTO POR SEXO E RAÇA

\begin{tabular}{|c|c|c|c|c|c|c|c|c|}
\hline \multirow[t]{2}{*}{ Variáveis } & \multicolumn{4}{|c|}{ RMSP } & \multicolumn{4}{|c|}{ RMS } \\
\hline & B & DP & $t$ & Sig $t$ & B & DP & $t$ & Sig $t$ \\
\hline \multicolumn{9}{|l|}{ Homem } \\
\hline Constante & 4,493000 & 0,034 & 133,10 & 0,00 & 4,067000 & 0,050 & 81,10 & 0,00 \\
\hline Escolaridade & 0,063800 & 0,003 & 23,39 & 0,00 & 0,082440 & 0,004 & 19,74 & 0,00 \\
\hline Estabilidade & 0,025630 & 0,001 & 37,98 & 0,00 & 0,014210 & 0,001 & 14,94 & 0,00 \\
\hline Experiência & 0,017520 & 0,002 & 8,15 & 0,00 & 0,011740 & 0,003 & 3,55 & 0,00 \\
\hline Experiência ao quadrado & $-0,000101$ & 0,000 & $-3,22$ & 0,00 & 0,000055 & 0,000 & 1,11 & 0,27 \\
\hline Escolarid x experiência & 0,000083 & 0,000 & 0,81 & 0,42 & $-0,000109$ & 0,000 & $-0,73$ & 0,47 \\
\hline Assalariado & $-0,021370$ & 0,012 & $-1,74$ & 0,08 & $-0,117000$ & 0,021 & $-5,62$ & 0,00 \\
\hline Autônomo & $-0,152000$ & 0,015 & $-10,16$ & 0,00 & $-0,324000$ & 0,024 & $-13,72$ & 0,00 \\
\hline LAMBDA & 0,684000 & 0,008 & 83,99 & 0,00 & 0,781000 & 0,013 & 58,36 & 0,00 \\
\hline $\mathrm{R}^{2}$ / Teste F / № Obs. & 0,59 & 3.718 & 20.643 & & 0,60 & 2.103 & 11.302 & \\
\hline \multicolumn{9}{|l|}{ Mulher } \\
\hline Constante & 4,084000 & 0,044 & 92,63 & 0,00 & 3,497000 & 0,056 & 62,18 & 0,00 \\
\hline Escolaridade & 0,094810 & 0,004 & 23,75 & 0,00 & 0,106000 & 0,005 & 20,55 & 0,00 \\
\hline Estabilidade & 0,036420 & 0,001 & 35,95 & 0,00 & 0,024340 & 0,001 & 21,50 & 0,00 \\
\hline Experiência & 0,025800 & 0,003 & 8,66 & 0,00 & 0,013590 & 0,004 & 3,53 & 0,00 \\
\hline Experiência ao quadrado & $-0,000263$ & 0,000 & $-6,13$ & 0,00 & $-0,000018$ & 0,000 & $-0,32$ & 0,75 \\
\hline Escolaridad $x$ experiência & $-0,000355$ & 0,000 & $-2,41$ & 0,02 & $-0,000194$ & 0,000 & $-1,07$ & 0,29 \\
\hline Assalariado & 0,123000 & 0,013 & 9,65 & 0,00 & 0,135000 & 0,018 & 7,58 & 0,00 \\
\hline Autônomo & $-0,486000$ & 0,018 & $-26,91$ & 0,00 & $-0,387000$ & 0,021 & $-18,86$ & 0,00 \\
\hline LAMBDA & 0,654000 & 0,019 & 35,11 & 0,00 & 0,749000 & 0,019 & 38,71 & 0,00 \\
\hline $\mathrm{R}^{2}$ / Teste F / № Obs. & 0,51 & 2.100 & 16.105 & & 0,58 & 1.746 & 10.283 & \\
\hline \multicolumn{9}{|l|}{ Branco } \\
\hline Constante & 4,270000 & 0,035 & 122,04 & 0,00 & 4,162000 & 0,115 & 36,17 & 0,00 \\
\hline Escolaridade & 0,070340 & 0,003 & 25,38 & 0,00 & 0,078580 & 0,009 & 8,56 & 0,00 \\
\hline Estabilidade & 0,030490 & 0,001 & 42,91 & 0,00 & 0,018580 & 0,002 & 9,36 & 0,00 \\
\hline Experiência & 0,007165 & 0,002 & 3,23 & 0,00 & $-0,013650$ & 0,007 & $-1,84$ & 0,07 \\
\hline Experiência ao quadrado & 0,000066 & 0,000 & 2,06 & 0,04 & 0,000438 & 0,000 & 4,12 & 0,00 \\
\hline Escolaridad $x$ experiência & 0,000468 & 0,000 & 4,44 & 0,00 & 0,000959 & 0,000 & 2,98 & 0,00 \\
\hline Assalariado & 0,073430 & 0,011 & 6,77 & 0,00 & $-0,137000$ & 0,035 & $-3,97$ & 0,00 \\
\hline Autônomo & $-0,215000$ & 0,014 & $-14,95$ & 0,00 & $-0,395000$ & 0,043 & $-9,20$ & 0,00 \\
\hline LAMBDA & 0,844000 & 0,010 & 84,83 & 0,00 & 0,966000 & 0,031 & 30,87 & 0,00 \\
\hline $\mathrm{R}^{2} /$ Teste F / № Obs. & 0,55 & 3.897 & 25.793 & & 0,60 & 628 & 3.327 & \\
\hline \multicolumn{9}{|l|}{ Negro } \\
\hline Constante & 4,573000 & 0,047 & 96,72 & 0,00 & 3,785000 & 0,041 & 92,43 & 0,00 \\
\hline Escolaridade & 0,034280 & 0,004 & 8,41 & 0,00 & 0,068130 & 0,004 & 19,25 & 0,00 \\
\hline Estabilidade & 0,031930 & 0,001 & 29,23 & 0,00 & 0,018660 & 0,001 & 22,63 & 0,00 \\
\hline Experiência & 0,012660 & 0,003 & 4,14 & 0,00 & 0,006874 & 0,003 & 2,51 & 0,01 \\
\hline Experiência ao quadrado & $-0,000162$ & 0,000 & $-3,68$ & 0,00 & 0,000043 & 0,000 & 1,06 & 0,29 \\
\hline Escolaridad $x$ experiência & 0,000181 & 0,000 & 1,07 & 0,29 & 0,000280 & 0,000 & 2,08 & 0,04 \\
\hline Assalariado & 0,223000 & 0,014 & 15,83 & 0,00 & 0,282000 & 0,014 & 20,78 & 0,00 \\
\hline Autônomo & $-0,061950$ & 0,018 & $-3,36$ & 0,00 & $-0,111000$ & 0,016 & $-6,92$ & 0,00 \\
\hline LAMBDA & 0,582000 & 0,010 & 56,72 & 0,00 & 0,752000 & 0,010 & 72,42 & 0,00 \\
\hline $\mathrm{R}^{2}$ / Teste F / № Obs. & 0,44 & 1.093 & 10.969 & & 0,53 & 2.546 & 18.245 & \\
\hline
\end{tabular}


Os assalariados costumam apresentar rendimentos mais perenes, de modo que acabam por assegurar uma média anual de ganhos mais elevada. No entanto, na medida em que não houve separação dos assalariados com e sem registro em carteira de trabalho, ${ }^{3}$ defronta-se com uma massa heterogênea de assalariados que dificulta qualquer afirmação acerca do sinal dessa variável. Vale lembrar que essa variável apresentou sinal negativo para os homens de Salvador e de São Paulo e para os brancos de Salvador.

Os trabalhadores autônomos representam o núcleo central das atividades econômicas informais. Esta variável apontou sinal negativo em todas as regressões. Como se sabe, a informalidade não necessariamente resulta em baixos rendimentos, isso porque existe uma proporção significativa desses trabalhadores que, com iguais atributos pessoais, auferem rendimentos superiores àqueles alcançados pelos trabalhadores formais (assalariados), enquanto que a maior parte deles recebe rendas significativamente baixas, de maneira que este contingente de baixos rendimentos acaba por influenciar negativamente o sinal dessa variável.

\subsection{Resultados da Decomposição de Oaxaca}

Para estimar o efeito de diferenças regionais sobre o mercado de trabalho dessas regiões, procedeu-se à decomposição de Oaxaca (1973). Procurou-se, então, comparar os diferenciais de rendimentos dos homens, das mulheres, dos brancos e dos negros nessas duas importantes regiôes metropolitanas do País. Procurou-se decompor os diferenciais de rendimentos médios em duas partes: uma atribuível às diferenças nas distribuições de atributos dos trabalhadores, e outra das diferentes dimensões, complexidades e características dos mercados de trabalho das regiões metropolitanas de São Paulo e de Salvador. A Tabela 8 mostra essa decomposição.

Pode-se observar (Tabela 8) que o efeito regionalização se apresenta como o mais importante elemento do diferencial de rendimentos do trabalho entre as regióes metropolitanas de São Paulo e de Salvador. Este diferencial é bem mais importante que o diferencial atribuído às diferenças nas distribuições dos atributos de inserção ocupacional dos trabalhadores nessas regióes. Isto se verifica para todos os agrupamentos de trabalhadores analisados. Em termos globais, o diferencial de rendimentos para a mulher apresenta-se como o mais elevado, seguindo-se o diferencial dos homens, negros e brancos. A parte desse diferencial atribuível à regionalização dos mercados de trabalho também se mostra mais elevada para a mulher, seguindo-se o negro, o homem e o branco. A parte do diferencial de rendimentos decorrente da dotação dos atributos de

3 A variável dummy assacart (assalariado com carteira $=1$ e demais $=0$ ) não se mostrou estatisticamente significativa, de modo que foi retirada das regressões. 
inserção ocupacional dos trabalhadores mostrou-se mais elevada para os homens, seguindo-se os negros, os brancos e finalmente as mulheres.

TABELA \& - DECOMPOSIÇÃO DE OAXACA, RENDIMENTOS MÉDIOS E DIFERENCIAL DE RENDIMENTOS POR GENERO E RAÇA

\begin{tabular}{lrrrc}
\hline Decomposição de Oaxaca & Homem & Mulher & Branco & Negro \\
\hline Efeito regionalização & 0,302 & 0,523 & 0,174 & 0,361 \\
Efeito diferença de dotação de atributos & 0,219 & 0,079 & 0,094 & 0,118 \\
Efeito total & 0,521 & 0,602 & 0,268 & 0,479 \\
Rendimentos médios (em R\$) & & & & \\
RMSP & 606,28 & 353,43 & 487,02 & 359,27 \\
RMS & 360,13 & 193,53 & 372,61 & 222,64 \\
Diferencial de Rendimentos (RMSP-RMS) & 246,15 & 159,90 & 114,42 & 136,63 \\
- Diferencial de regionalização & 142,74 & 138,80 & 74,28 & 102,97 \\
• Diferencial de atributos & 103,40 & 21,10 & 40,13 & 33,65 \\
\hline
\end{tabular}

Especificamente para o grupo de trabalhadores do sexo feminino, os diferenciais de rendimento do trabalho em favor da RMSP, relativamente à RMS, devido à regionalização, correspondem a 86,9\%, enquanto que os diferenciais de dotação de atributos produtivos contribuem com apenas 13,1\% para os diferenciais de rendimentos entre essas duas regiões. Para os trabalhadores do sexo masculino, a regionalização é responsável por $58 \%$ dos diferenciais positivos de rendimentos do trabalhador na RMSP vis-à-vis aos da RMS, enquanto que o diferencial de atributos de inserção ocupacional contribui com $42 \%$ para esse diferencial de rendimentos.

Padrão semelhante ocorre com os trabalhadores agrupados em diferentes raças. Isto é, 64,9\% dos diferenciais de rendimentos em favor dos brancos da RMSP, relativamente aos brancos da RMS, podem ser explicados pelas diferenças regionais, de modo que apenas $35,1 \%$ são resultantes de diferenças na dotação de atributos de inserção ocupacional dos trabalhadores nessas duas regiốes. Os diferenciais de rendimentos dos negros da RMSP em relação aos negros da RMS, que resultam de diferenças regionais, correspondem a $75,4 \%$, enquanto que as diferenças de atributos contribuem com $24,6 \%$ para esses diferenciais de rendimentos. 
Uma avaliação dos rendimentos, em valores monetários, nas duas regiões comprova os diferenciais já apontados. ${ }^{4}$ Assim é que na região metropolitana de São Paulo o diferencial de rendimentos médios decorrente da regionalização foi estimado em RS 142 para os homens, R\$ 138 para as mulheres, R\$ 102 para os negros e, por fim, R \$ 74 para os brancos, enquanto que os diferenciais originários na dotação de atributos mostram-se mais elevados para os homens ( $\mathrm{R} \$ 103$ ), seguindo-se os brancos (R\$ 40), os negros (R\$ 33) e as mulheres ( $\mathrm{R}$ \$ 21). Estes resultados confirmam que a região metropolitana de São Paulo, em relação à de Salvador, remunera mais seus trabalhadores, seja na perspectiva da dotação de fatores produtivos, em virtude dos trabalhadores de São Paulo possuírem relativamente mais atributos valorizados pelo mercado, seja na perspectiva da regionalização do espaço econômico, diante da maior concentração econômica e aglomeração de atividades econômicas nessa região.

Deve-se ressaltar que o diferencial regional de rendimentos pode ser entendido como uma caixa-preta bastante complexa, dado que uma série de fatores contribui para a existência do mesmo. Uma forma de abrir esta caixa-preta, ainda que de maneira parcial, pode ser via análise da disparidade dos padrões de vida, dado que os diferenciais atribuídos ao poder de compra dos rendimentos dessas regióes podem ser menores que os diferenciais de rendimentos, na medida em que uma mesma cesta de bens é avaliada de maneira diferenciada nas duas regiões metropolitanas. Uma forma de tornar esse diferencial mais próximo de uma caracterização regional seria observar esses rendimentos pela ótica do gasto com consumo, refletindo melhor o diferencial de padrão de vida entre as regiôes. Estudos mostram que esses resultados podem ser bem diferentes em relação aos diferenciais de rendimentos. Uma análise acerca dessa problemática pode ser encontrada em Siqueira e Hamasaki (2000).

\section{CONSIDERAÇÕES ADICIONAIS E CONCLUSÕES}

Fazendo uso das bases de microdados da Pesquisa de Emprego e Desemprego (PED) das regiões metropolitanas de São Paulo e de Salvador, este artigo buscou estimar e comparar os determinantes dos rendimentos do trabalho dessas duas importantes regióes, isolando o aspecto regional responsável por possíveis diferenciais de rendimentos, das diferenças nas dotações de atributos produtivos desses agrupamentos de trabalhadores.

4 A grande diferença existente entre as médias dos rendimentos originários das regressões e aquelas apontadas na parte estatística (primeira seção) deste trabalho pode ser explicada pelo fato de que, nas regressões, foram consideradas apenas as pessoas com rendas positivas do trabalho e com idade entre 18 e 65 anos. Este filtro possibilitou um corte proporcionalmente maior para elevados rendimentos do trabalho que os ganhos de rendimentos médios proporcionados pela consideraçáo dos rendimentos positivos. Assim, fica notória a subavaliação desses mesmos rendimentos. 
Aplicando um modelo binomial probit, foram estimadas, pelo método de máxima verossimilhança, equações de participação segundo o gênero e a raça (brancos e negros) das duas regiões. Objetivando corrigir os possíveis vieses de seleção, aplicou-se, com base nos coeficientes estimados nas equações de participação, o procedimento de Heckman (1979). Este procedimento permitiu construir a variável lambda, ou razão inversa de Mills, com a qual se ajustou a equação de rendimentos para cada segmento de trabalhadores analisado. Com isso, alcançam-se estimativas dos parâmetros consistentes e não enviesadas quanto à seletividade da amostra, em decorrência do fato de apenas as pessoas ocupadas e com rendimentos positivos estarem presentes nos cálculos dos determinantes dos rendimentos. Em seguida, procedeu-se à decomposição de Oaxaca (1973), objetivando separar os determinantes dos rendimentos do trabalho que podem ser explicados pelas dotações intrínsecas dos trabalhadores, em termos de seus respectivos atributos pessoais, daqueles determinantes não explicáveis por tais atributos, os quais podem ser considerados como oriundos das características específicas de cada uma das regiões analisadas.

Os resultados obtidos confirmam a existência de uma significativa diferenciação de rendimentos do trabalho entre as regiões metropolitanas de São Paulo e de Salvador. A diferenciação de rendimentos do trabalho entre essas regiões se apresenta como o resultado de dois efeitos distintos: um proveniente da remuneração dos atributos de inserção ocupacional dos trabalhadores e o outro, significativamente mais relevante, originário das especificidades das estruturas econômicas regionais, as quais expressam a organização de cada um dos mercados de trabalho. Desta forma, observa-se que os trabalhadores da região metropolitana de São Paulo, relativamente àqueles de Salvador, recebem mais por possuírem dotações mais elevadas de atributos de inserção ocupacional e por se encontrarem na região metropolitana de São Paulo, região esta que, em virtude da maior concentração e aglomeração econômica, propicia a seus trabalhadores maiores rendimentos do trabalho.

\section{REFERENNCIAS BIBLIOGRÁFICAS}

DEATON, A.; MUELLBAUER, J. Economics and consumer behavior. Cambridge: Cambridge University Press, 1980.

DEDECCA, C. Les années 1990, stabilité et inegalité de la societé brésilienne. Revue Tiers Monde, 167, Paris: PUF, 2001.

DUTOIT, L; LAMBELET, J-C. $\Upsilon$ a-t-il vraiment discrimination salariale contre les femmes? Disponível em: http://www.hec.unil.ch.modmacro, 2001.

FERNANDES, R. Mercado de trabalho não regulamentado: participação relativa e diferenciais de salários. Pesquisa e Planejamento Económico, v. 26, n. 3, 1996.

GREENE, W. Econometric analysis. New Jersey: Prentice-Hall, 1993. 
HECKMAN, J. Sample selection bias as a specification error. Econometrica, v. 47, n. 1, p. 153-161, 1979.

JOHNSTON, J; DINARDO, J. Econometric methods. New York: McGraw-Hill. 1997.

LEME, M. Carolina da Silva; WAJNMAN, Simone. Diferenciais de rendimento por gênero. In: LISBOA, M. de B; MENEZES-FILHO, N. A. (orgs.), Microeconomia e sociedade no Brasil. Rio de Janeiro: Contra Capa - FGV/EPGE, 2001.

LOUREIRO, P. R. A; CARNEIRO, F. G. Discriminação no mercado de trabalho: uma análise dos setores rural e urbano no Brasil. Economia Aplicada, v. 5, n. 3, p. $519-545$, jul./set. 2001.

MALAN, P.; WELLS, J. Distribuição de renda e desenvolvimento econômico no Brasil. In: TOLIPAN, R.; TINELLI, A. C. A controvérsia sobve distribuição de renda e desenvolvimento. Rio de Janeiro: Zahar Editores, 1978.

MENEZES-FILHO, Naércio A.; PICCHETTI, Paulo. Desemprego. In: LISBOA, Marcos de Barros; MENEZES-FILHO, N. A. (orgs.), Microeconomia e sociedade no Brasil. Rio de Janeiro: Contra Capa - FGV/EPGE, 2001.

OAXACA, R. Male-female wage differentials in urban labor markets. International Economic Review, 14, p. 693-709, 1973.

SACCONATO, A. L; MENEZES FILHO, N. A. A diferença salarial entre os trabalhadores americanos e brasileiros: uma análise com microdados. São Paulo: IPE-USP, Texto para discussão, 25/2001.

SILVA, N. de Deus Vieira; KASSOUF, A. L. Mercados de trabalho formal e informal: uma análise da discriminação e da segmentação. Nova Economia, v. 19, n. 1, jul. 2000.

SIQUEIRA, R. B; HAMASAKI, C. S. Gasto, renda e desigualdade no Brasil: um estudo comparativo entre as regiões Nordeste e Sudeste. REN, v. 31, n. Especial, 2000.

VARIAN, Hal R. Microeconomics analysis. New York: Norton, 1978.

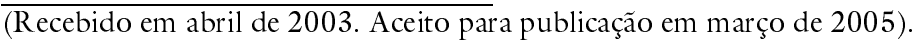

